\title{
Radionuclide Chemistry in Nuclear Facilities Based on Heavy Liquid Metal Coolants: Past, Present and Future
}

\author{
Jörg Neuhausen*
}

\begin{abstract}
Heavy liquid metals such as lead and lead bismuth eutectic (LBE) are considered as spallation target material for next-generation neutron sources and as coolant of fast spectrum nuclear reactors that are developed to facilitate more efficient use of nuclear fuel as well as transmutation of long-lived nuclear waste. During the operation of such facilities, the heavy liquid metal will be activated by nuclear reactions. Additionally, fission product radionuclides may be introduced into the liquid metal from leaking fuel pins or by fission of the target nuclei in spallation. The chemical behaviour of these radioactive contaminants in the liquid metal - especially their immediate volatilization or volatilization of formed secondary compounds - may affect the safety of such facilities. The present article summarizes the activities of PSI's Laboratory of Radiochemistry towards a better understanding of the chemistry of potentially hazardous radionuclides in LBE and discusses aspects that need to be addressed in future to support the licensing of heavy liquid metal-based nuclear facilities.
\end{abstract}

Keywords: Accelerator Driven System · Gas phase radiochemistry · Gen IV reactors · Spallation targets · Transmutation

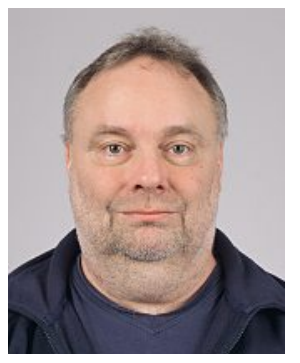

Jörg Neuhausen acquired a $\mathrm{PhD}$ in solidstate chemistry at Johannes Gutenberg University in Mainz in 1995. Afterwards, he held a permanent position at the same university, working on high temperature synthesis of new materials. In 2002, he joined the Paul Scherrer Institute, where he contributed to the successful licensing of the MEGAPIE prototype liquid metal spallation target. Since then, he continues to contribute to the development of heavy liquid metal technology through research performed within several EU projects as member of the 'Isotope and target chemistry' group of PSI's Laboratory of Radiochemistry (LRC). His interests comprise intermetallic interactions and the chemical behaviour of radionuclides in molten metals.

\section{Introduction}

The safe and sustainable exploitation of nuclear energy requires the development of new technologies that enhance fuel efficiency and reduce the hazard of spent nuclear fuel. Fuel efficiency can be increased by utilizing breeder reactors together with a closed fuel cycle, while the hazard of spent nuclear fuel may be mitigated by transmutation of its long-lived radioactive components to shorter-lived ones. ${ }^{[1]}$ Among the novel nuclear reactor types designed for these purposes, systems utilizing liquid lead and lead bismuth eutectic (LBE) as reactor coolant and spallation target material take a prominent position because these liquid metals show a number of favourable physical and chemical characteristics that make their use advantageous from both a technical as well as a safety point of view. ${ }^{[2]}$ One general advantage of the use of lead and LBE as coolant of nuclear reactors is their high boiling point, which enables low-pressure operation of the reactors and makes accident scenarios with a loss of coolant highly

${ }^{*}$ Correspondence: Dr. J. Neuhausen, E-mail: joerg.neuhausen@psi.ch Laboratory of Radiochemistry, Paul Scherrer Institut, Forschungsstrasse 111 $\mathrm{CH}-5232$ Villigen-PSI, Switzerland unlikely. Furthermore, the non-moderating properties of lead and LBE allow the design of breeder reactors utilizing a fast neutron spectrum, such as the Lead-Cooled Fast Reactor (LFR) developed within the generation IV (Gen IV) initiative. ${ }^{[3]}$ In comparison to the liquid sodium coolant used in previous fast breeder reactors, liquid lead coolant is chemically much less reactive. Thus, its use considerably simplifies some aspects of the required coolant technologies and enhances the chemical safety of the system.

For the transmutation of actinides, which represent the largest hazard in the spent fuel of conventional light water reactors, a particularly useful reactor concept is the so-called Accelerator Driven System (ADS). In such a reactor, a subcritical reactor core is coupled with a proton accelerator. The high energy protons emitted from the accelerator interact with a spallation target located in the reactor core to generate additional neutrons, sustaining the nuclear chain reaction. ${ }^{[4]}$ This neutron generation process is most efficient when heavy elements with neutron-rich nuclei are used as spallation target material. Since lead and LBE fulfil this criterion, they are ideally suited to simultaneously serve as reactor coolant and spallation target material in an ADS. A favourable safety feature of the ADS concept is that the reactor can be quickly shut down by switching off the accelerator followed by convective cooling.

Nuclear reactors based on pure lead as coolant are planned to be operated at relatively high temperatures in the range of 500 to $600{ }^{\circ} \mathrm{C}$. LBE has a much lower melting point $\left(125.5^{\circ} \mathrm{C}\right)$ compared to pure lead $\left(327^{\circ} \mathrm{C}\right) . .^{5]}$ Thus, facilities utilizing the eutectic alloy with a composition of 55.5 mass \% bismuth and 44.5 mass \% lead can be operated at considerably lower temperatures, mitigating for example corrosion problems that would occur at the operating temperatures needed for systems based on pure lead. For this reason, LBE can be seen as a temporary solution to be used in facilities that serve for developing the technologies finally needed for the pure lead systems, while at the same time demonstrating the viability of heavy liquid metal based nuclear technologies. ${ }^{[6]}$

As for all nuclear facilities, the potential release of volatile radioactive material into the environment is an issue that needs to be addressed to ensure the safe operation of heavy liquid metal cooled reactors. The radionuclide inventory of lead and LBE 
cooled reactors differs from that of conventional nuclear reactors because additional radionuclides are formed by activation of the coolant. The most prominent example for a highly radiotoxic and potentially volatile radionuclide specifically formed in this type of reactor is the $\alpha$-emitting polonium isotope ${ }^{210} \mathrm{Po}$. This nuclide is generated by neutron activation of bismuth. Therefore, it is especially relevant for LBE-based systems. However, it is formed also in smaller amounts in lead-cooled reactors from bismuth impurities. Other radionuclides produced by the activation of the coolant include isotopes of the elements mercury and thallium. In an ADS, additionally radioisotopes of practically all chemical elements are generated by spallation reactions induced by high energy protons. An assessment of the relative safety relevance of the produced nuclides clearly shows that polonium is the most hazardous element. ${ }^{[6]}$ Besides radionuclides produced by activation of the LBE, also fission products may ingress into the liquid metal from defect fuel pins. This includes noble gases as well as nuclides of potentially volatile elements such as iodine, caesium and tellurium. Furthermore, activated corrosion products will be entrained into the fast flowing heavy liquid metal coolant from the construction materials of the reactor vessel.

These radionuclides may undergo chemical reactions with the liquid metal coolant and potentially among each other as well as with corrosion products. The retention of radionuclides in the lead or LBE coolant of nuclear systems will depend on these chemical interactions and the chemical state finally adopted by the radioactive elements. Therefore, a solid understanding of these chemical processes is crucial for the safety assessment of such facilities. Apart from volatilization processes, also the deposition of radioactive material on surfaces of heat exchangers, pumps, the free surfaces above the coolant, or their intentional accumulation in cold traps used for purification, are processes governed by chemical effects that are important for reactor design and operation. ${ }^{[6]}$

The present paper summarizes results of chemical research performed within the last two decades towards a better understanding of chemical effects in liquid LBE relevant for its use in nuclear systems, focusing on contributions of the Laboratory for RadioChemistry (LRC) at Paul Scherrer Institut (PSI) in Villigen, Switzerland.

\section{Historical Context}

\subsection{The MEGAPIE Target}

Towards the end of the 1990s, the development of ADS technology reached a maturity level where components of the system were envisaged to be built and tested in large-scale demonstrator studies. The Paul Scherrer Institute (PSI) in Villigen, with its spallation neutron facility SINQ operating successfully with a solid target since $1996,{ }^{[7]}$ was ideally suited to host a demonstrator experiment for a liquid metal spallation target. Therefore, the MEGAPIE (MEGAwatt Pilot Experiment) initiative was launched as a collaboration of several European research institutions, with partners from Japan, Korea and the USA joining in a later phase, with the aim of demonstrating the feasibility of designing, building, operating and exploring a liquid LBE spallation target of 1 MW beam power at PSI. ${ }^{[8]}$

The operation of such a target required adhering to stringent licensing procedures. In particular, the release of radioactive nuclides produced during the operation of the target was of concern. Consequently, the licensing authority required a proof that the potential release of radioactive species in accident scenarios was low. To ensure this, the thermal release of volatile radionuclides from the liquid LBE had to be studied.

\subsubsection{Theoretical Studies}

One particular concern with respect to the release of volatile radionuclides into the environment was the behaviour of the high- ly radiotoxic polonium, as outlined in the introduction. The physicochemical data available in the literature for this element and its compounds are rather scarce, and sometimes of questionable quality. The lack of consistent data is caused by the fact that all isotopes of the element are radioactive. Therefore, samples are only available in small quantities, and they are difficult to handle because of their decay properties. The most accessible isotope ${ }^{210} \mathrm{Po}$ has a relatively short half-life (138 days). As a consequence, it has a large decay heat $(140 \mathrm{~W} / \mathrm{g})$, hampering measurements of thermodynamic quantities by its in situ heat generation. Therefore, it was deemed mandatory for the licensing of MEGAPIE to perform a consistency check on all available thermochemical data on polonium and its compounds with lead, bismuth and the common elements oxygen and hydrogen, and to derive missing data using empirical correlations and extrapolations based on the properties of polonium's lighter homologues oxygen, sulphur, selenium and tellurium. The results of these studies indicated that the experimental data on the vapour pressure of pure polonium and lead polonide might be affected by the effects of decay heat, leading to an overestimation of the volatility of polonium especially at low temperatures (Fig. 1). ${ }^{[9-12]}$ Estimations of thermodynamic data of polonium compounds indicated that the formation of the very volatile molecule $\mathrm{H}_{2} \mathrm{Po}$ - a compound often postulated as particularly dangerous - is only possible in presence of nascent hydrogen, while in atmospheres containing molecular hydrogen or water its formation is thermodynamically not favourable. ${ }^{[12]}$

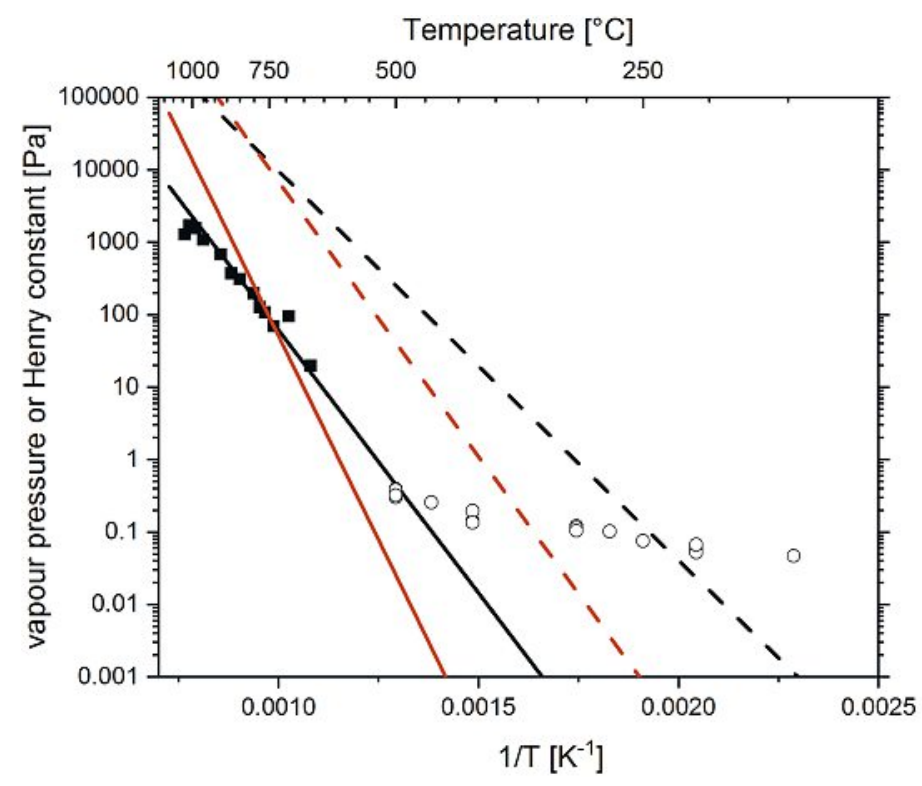

Fig. 1. Comparison of vapor pressure data of pure polonium, lead polonide and the Henry constant of polonium dissolved in LBE. The Henry constant is defined as $k_{H^{\prime} P_{O}}=p_{P_{O}} / x_{P_{0}}$, with $p_{P_{O}}$ being the equilibrium vapour pressure of the solute polonium over an ideal dilute solution with the concentration given as mole fraction $x_{P_{0}}$. Dashed lines: pure polonium (black: derived from experimental data; ${ }^{[10]}$ red: derived by extrapolation of thermodynamic data of the lighter homologues of polonium; ${ }^{[9]}$ Solid lines: lead polonide PbPo (black: derived from experimental data; ${ }^{[11]}$ red: derived by extrapolation of thermodynamic data of $\mathrm{PbS}$, $\mathrm{PbSe}, \mathrm{PbTe} ;{ }^{[12]}$ black squares: polonium dissolved in LBE, derived from high temperature experimental data; ${ }^{[16]}$ open circles: apparent Henry constant of polonium dissolved in LBE, low temperature experimental data. ${ }^{[34]}$

Apart from assessing the thermodynamic data of polonium and its stoichiometric binary compounds, an additional effort was undertaken to determine thermodynamic data for polonium in dilute solution in liquid metals. For this purpose, the semi-empirical Miedema model was used. This model allows the calculation of 
enthalpies of mixing, compound formation and dissolution for binary combinations of two elements in the condensed phase based on parameters derived from electronegativity, electron density and size of the atoms. ${ }^{[13]}$ However, for the element of interest, polonium, no parameter set was available. Therefore, a set of Miedema parameters was developed for the elements of the chalcogen group, which enabled the estimation of the enthalpies of solution of polonium in liquid lead and bismuth. ${ }^{[14]}$ These data were used together with the extrapolated thermodynamic data for various gaseous binary polonium containing molecules to assess different reaction pathways for the evaporation of polonium from LBE. [12] The results indicated that polonium most likely evaporates from $\mathrm{LBE}$ in the form of lead polonide, $\mathrm{PbPo}$.

\subsubsection{Experimental Studies}

While the results of the theoretical evaluations were self-consistent, they were considered to be of limited absolute accuracy. Therefore, relying solely on these results for the safety assessments required for the licensing of MEGAPIE was deemed insufficient. As a consequence, experimental studies were performed at LRC on the evaporation of polonium and radionuclides of other safety-relevant volatile elements from LBE. The method employed for these studies was the transpiration method, a simple yet effective method for the determination of vapour pressures of pure substances as well as Henry constant data for dilute solutions of a substance in a solvent. The method is based on quantifying the amount of substance evaporated from a sample in a saturated stream of carrier gas as illustrated in Fig. 2.[15]

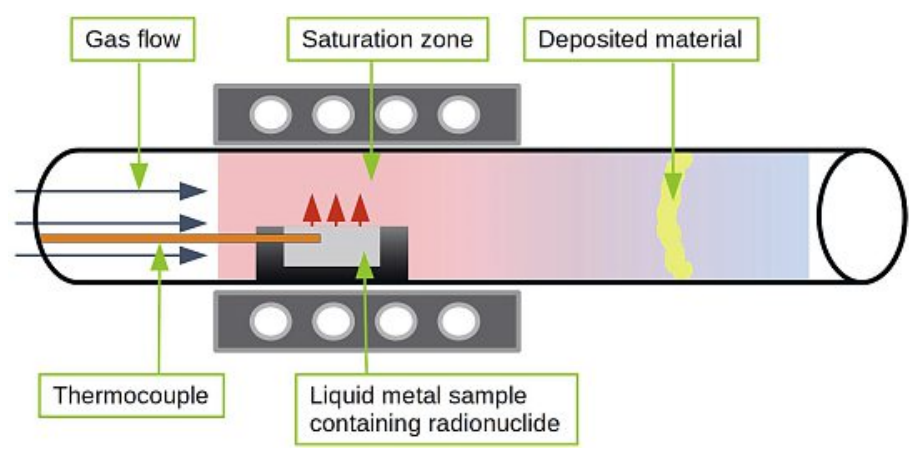

Fig. 2. Schematic representation of a typical transpiration setup. The carrier gas is saturated with the evaporated species in the hot saturation zone. In the cold deposition zone, the evaporated material is condensed and can be collected. The amount of evaporated material can be either determined from the loss of sample material or the amount of deposited material.

The first setup for transpiration experiments developed at LRC consisted simply of a fused silica tube heated by a self-made resistance furnace through which a stream of dried $\mathrm{Ar} / 7 \%-\mathrm{H}_{2}$ carrier gas was flushed with a known flow rate. The samples consisted of LBE that was doped with ${ }^{206}$ Po. Similar experiments with radionuclides of polonium's lighter homologues selenium $\left({ }^{75} \mathrm{Se}\right)$ and tellurium $\left({ }^{121} \mathrm{Te}\right)$ were also performed. The samples were prepared by implantation of mass-separated radioactive ion beams of the radiotracers or their precursors at the on-line isotope separator ISOLDE at CERN. ${ }^{[16]}$ Similar experiments were also performed on LBE samples doped with radiotracers of other volatile elements that are relevant in the context of LBE-based nuclear facilities such as mercury, thallium and iodine. ${ }^{[17]}$ The radiotracers for the latter studies were obtained by neutron activation at the Neutron Irradiation Service (NIS), which is operated by LRC at the SINQ facility of PSI. Typical concentrations of the non-carrier-added radiotracers in the LBE were mole fractions in the order of $10^{-12}$ to $10^{-13}$. In spite of these extremely small concentrations, the amount of tracer contained in the LBE can be accurately determined by the radiometric methods available at LRC ( $\alpha$ - and $\gamma$-spectrometry and liquid scintillation counting (LSC)). In the experiments described above, $\gamma$-spectrometry was used to measure the amount of radiotracer in the sample before and after an experiment. Transpiration experiments were performed at various temperatures ranging from 150 to $1032{ }^{\circ} \mathrm{C}$. For polonium, measureable evaporation was detected only at temperatures $>600{ }^{\circ} \mathrm{C}$.

\subsubsection{Safety Assessment for the Licensing of MEGAPIE}

For the licensing of the MEGAPIE experiment, the data of the transpiration experiments described above were evaluated quantitatively. From the difference of the amounts of radiotracer present before and after an experiment at a certain temperature, the amount of substance carried with the known gas volume can be determined. Vapour pressure and Henry constants can then be calculated assuming ideal gas behaviour. In this way, temperature dependent Henry constant data were determined for diluted solutions of polonium, mercury and iodine in liquid LBE and the evaporation rate of polonium from LBE was determined. ${ }^{[18]}$ The results of these evaluations for polonium are compared with experimental and extrapolated vapour pressure data of pure polonium and lead polonide in Fig. 1. When the Henry constant of polonium in $\mathrm{LBE}, k_{\mathrm{H}, P o}$, is defined as

$$
k_{\mathrm{H}, P o}=p_{P o} / x_{P o}
$$

with $p_{P o}$ being the equilibrium vapour pressure of the solute polonium over an ideal dilute solution with the concentration of polonium given as mole fraction $x_{P o}$, the influence of the solvent on the volatility can be directly visualized by comparing with the vapour pressure of the pure element or its compounds with components of the solvent. The comparison in Fig. 1 shows that at temperatures between $\mathrm{ca} .600$ and $1000{ }^{\circ} \mathrm{C}$ the vapour pressure of polonium is reduced - compared to elemental polonium - when it is dissolved in LBE. In fact, in this temperature range polonium dissolved in LBE behaves much like an ideal solution of lead polonide. These data were used in an assessment of the consequences of various complex accident scenarios for the MEGAPIE target, in which the maximum activity released to the public was determined. ${ }^{[19]}$ These evaluations demonstrated to the licensing authority that the maximum dose experienced by the public in case of a worst case accident could be kept below the required limit of $1 \mathrm{mSv}$ if certain additional safety measures such as installing redundant earthquake resistant filtering units are taken. Based on these assessments, the MEGAPIE experiment was licensed and successfully operated from August to December 2006, delivering $80 \%$ higher neutron flux compared to a conventional solid spallation target. ${ }^{[20]}$ The successful licensing and operation of the MEGAPIE target constituted a major milestone for the development of ADS and liquid metal technologies for nuclear applications in general. ${ }^{[21]}$

\subsubsection{Post Irradiation Examination of the MEGAPIE Target}

The stable and efficient performance of the MEGAPIE target during operation indicates the extraordinary potential of liquid metal technology for nuclear systems. The Post Irradiation Examination (PIE) of the target, performed after a decay period of several years necessary to reduce its radioactivity to manageable levels, was equally important for the many scientists and engineers all over the world involved in the project. ${ }^{[22]}$ The extensive PIE Program was performed to investigate the influence of the intense irradiation on the properties of the structure materials as well as to experimentally determine the radionuclide inventory and the distribution of radionuclides in the target. 
For the radioanalytical studies, more than 70 samples were extracted from the target in PSI's Hot Laboratory, representing different positions comprising bulk LBE as well as samples from the interfaces of LBE with the walls of the target vessel and the cover gas. In these samples, 20 radionuclides were quantified using $\alpha$ - and $\gamma$-spectrometric methods at PSI and accelerator mass spectrometry (AMS) at ETH Zurich. Furthermore, also their spatial distribution within the target was determined. ${ }^{[23]}$ The most important findings can be summarized as follows:

The results of radiochemical analyses can be used as benchmark for nuclear physics codes for the quantitative prediction of radionuclide production. ${ }^{[24]}$ For most of the radionuclides, the results of the analyses agreed well with theoretical predictions of the radionuclide inventory performed by colleagues from CEA/ Saclay and ESSS Lund, using calculation codes and models such as INCL/ABLA, MCNPX or FLUKA. Cases where significant discrepancies were found can be used to detect flaws in the codes and models and improve them.

It was found that the spatial distribution of many of the radionuclides in the target is strongly inhomogeneous. While nuclides of relatively noble metals such as $\mathrm{Au}, \mathrm{Hg}$ and $\mathrm{Po}$ were found to be more or less homogeneously dissolved in the bulk LBE, nuclides of strongly electropositive elements such as Ba and the lanthanides were found to accumulate on surfaces. Therefore, they are depleted in the bulk LBE. ${ }^{[23,25-28]}$ Surface enrichment was also found for electronegative elements such as chlorine and iodine. ${ }^{[23,29]}$ These findings may be important for the safety assessment of nuclear installations, especially concerning dose rate estimations and the evaluation of structure material damage. A plausible explanation for the accumulation of electropositive and electronegative elements at surfaces would be their integration in the lattice of surface oxide layers in cationic or anionic form, respectively.

\subsection{The Project SEARCH: Towards Licensing of the MYRRHA Reactor}

After the successful operation of the MEGAPIE target at PSI the efforts to build a demonstrator reactor for an ADS were strengthened. A major step into this direction is the development of the MYRRHA reactor (Multi-purpose hYbrid Research Reactor for High-tech Applications) at the Belgian Nuclear Research centre SCK•CEN. ${ }^{[30]}$ Meanwhile, the knowledge generated in preceding projects had been collected in an extensive 'Handbook on Lead-bismuth Eutectic Alloy and Lead Properties, Materials Compatibility, Thermalhydraulics and Technologies' published by the Nuclear Energy Agency (NEA) of the OECD, with LRC being responsible for the section dealing with the aspects of radionuclide chemistry in heavy liquid metals.[31] Based on the data collected in this document, it was concluded that for the licensing of a large-scale facility such as MYRRHA, with much larger accumulation of potentially hazardous radionuclides compared to the MEGAPIE target, additional studies on the volatilization of radionuclides and their deposition in the reactor were mandatory. These investigations were performed within the EURATOM FP6 project SEARCH (Safe ExploitAtion Related CHemistry for HLM reactors). ${ }^{[32]}$ The focus of LRC's contribution to this project was a more complete and detailed study of the evaporation and deposition behaviour of polonium. In particular, it was intended to generate reliable data on the equilibrium evaporation of polonium from LBE in the operation temperature range of the MYRRHA reactor $\left(200-400{ }^{\circ} \mathrm{C}\right)$. Compared to the transpiration experiments performed for MEGAPIE licensing, where data could only be acquired at temperatures $>600{ }^{\circ} \mathrm{C}$, this required substantially increasing the sensitivity of the experiments as well as verifying saturation of the carrier gas. The former was achieved by increasing the duration of the evaporation period, using long counting times for activity determination and by sampling of the evaporated material instead of measuring the difference of the polonium content of the sample before and after the experiment. Saturation was verified by performing measurements at different carrier gas flow rates. ${ }^{[15]}$

In addition to the transpiration experiments, thermochromatography experiments were also performed, with the goal to identify different chemical species of polonium forming under various chemical conditions, including inert $(\mathrm{He})$, reducing $\left(\mathrm{H}_{2}\right)$ and oxidizing $\left(\mathrm{O}_{2}\right)$ gases at different moisture levels, and to find materials suitable for capturing volatile polonium by adsorption. In this method, a sample containing carrier-free amounts of a radiotracer is evaporated in a gas stream and transported into a chromatography column exposed to a negative temperature gradient (Fig. 3). From the deposition temperature and other experimental parameters the adsorption enthalpy can be determined. ${ }^{[33]}$ In favourable cases, the transported gas phase species can be deduced.
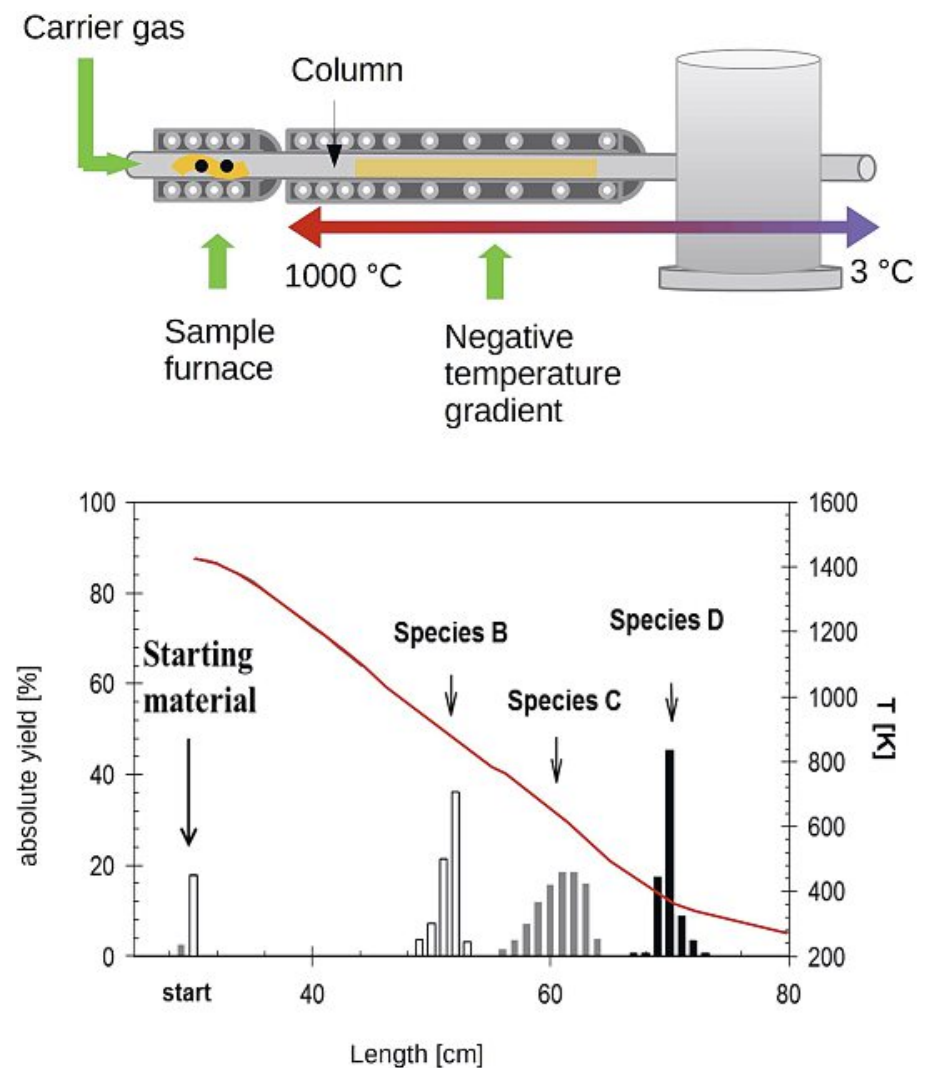

Fig. 3. Top: schematic representation of a typical thermochromatography setup. The sample is evaporated in a carrier gas stream and transported into the chromatography column exposed to a negative temperature gradient, where it deposits; Bottom: schematic representation of a thermochromatogram with three different species deposited along the temperature gradient shown as red line.

In parallel to the studies performed at LRC, additional experimental and theoretical studies were performed within the SEARCH project by partners at SCK $\cdot C E N$ and the University of Gent. These two groups focused on transpiration experiments complementing those performed at LRC and on theoretical studies on the interaction of polonium with lead, bismuth and LBE and potential better materials by Density Functional Theory (DFT).

The results of transpiration experiments performed within SEARCH showed that at temperatures below $500{ }^{\circ} \mathrm{C}$ the evaporation of polonium was higher than expected from extrapolating the high temperature data determined during MEGAPIE licensing (open circles in Fig. 1). ${ }^{[34]}$ This behaviour was later shown to be a non-equilibrium phenomenon related to the incorporation of polonium into a surface oxide layer. ${ }^{[35,36]}$ Therefore, the corresponding data shown in Fig. 1 are designated as apparent Henry constants. 
Thermochromatography experiments in fused silica tubes showed that volatile polonium species form in moist helium and hydrogen atmosphere but not in dry helium and hydrogen (Fig. 4). [37] This confirmed the results of earlier thermodynamics studies indicating that $\mathrm{H}_{2} \mathrm{Po}$ does not readily form when polonium is exposed to molecular hydrogen.

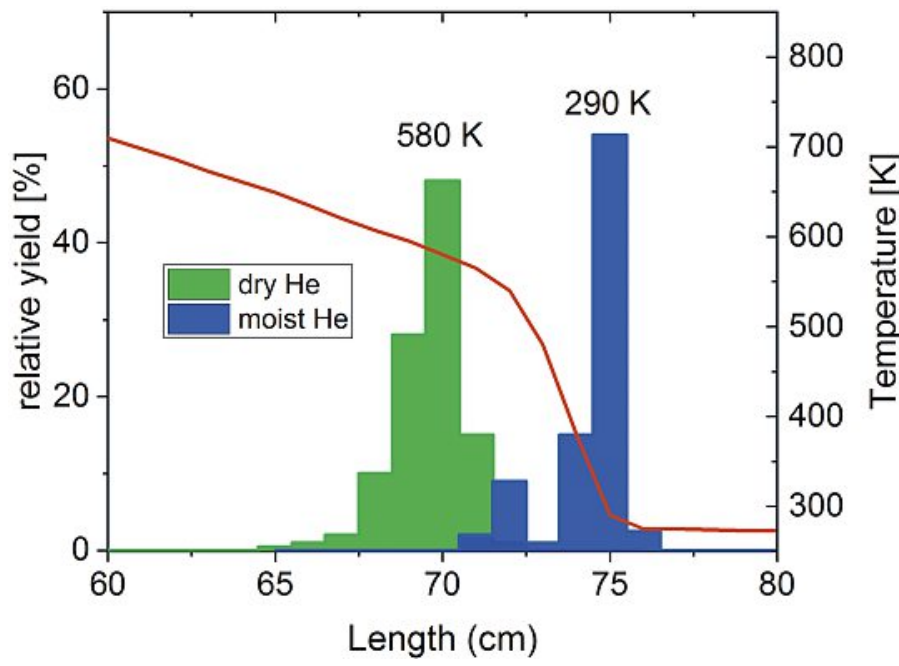

Fig. 4. Comparison of polonium depositions observed in thermochromatography experiments using ${ }^{206} \mathrm{Po}$ separated from proton-irradiated bismuth samples in fused silica columns in dry and moist helium carrier gas. In dry helium (green), polonium deposits at $580 \mathrm{~K}\left(307^{\circ} \mathrm{C}\right)$, presumably as bismuth polonide or monoatomic polonium. In moist helium (blue), polonium forms much more volatile compounds that deposit around room temperature $(290 \mathrm{~K})$. The temperature gradient is shown as red line. Graph adapted from Maugeri et al. ${ }^{[3]}$

The observation of particularly volatile polonium species in thermochromatography experiments was confirmed in transpiration experiments performed at $\mathrm{SCK} \bullet \mathrm{CEN}$ where polonium was evaporated from LBE in a moist argon stream. ${ }^{[35]}$ The fact that the volatile polonium species are consistently formed in moist atmospheres indicate that they most likely are polonium hydroxides or oxy-hydroxides. Thermochromatography experiments studying the adsorption of polonium on the noble metals gold, silver platinum and palladium show that these metals bind polonium strongly and thus are promising candidates for developing absorbers for polonium. ${ }^{[38]}$ The measured adsorption enthalpies agree well with results obtained by DFT-calculations on the adsorption interaction of monoatomic polonium with these noble metal surfaces performed at University of Gent.[39]

The main conclusion from the chemistry results of the SEARCH project with respect to the safe operation of an LBEcooled ADS is that care has to be taken to avoid the potential formation of volatile polonium compounds. Based on this finding the design of MYRRHA has been adapted to include double-walled heat exchangers instead of the originally foreseen single-walled option.

\section{Recent Results: The EURATOM H2020 project MYRTE}

The results obtained in the SEARCH project raised a number of questions that need to be answered to ensure a safe operation of the MYRRHA reactor. For this purpose, a work package on 'Chemistry of volatile radionuclides' was incorporated into the project MYRTE performed from 2015 to 2019 in the EURATOM H2020 framework. ${ }^{[40]}$ The work was performed by the same groups at SCK•CEN, University of Gent and LRC that already collaborated successfully in the SEARCH project. The topics that were studied at $\mathrm{SCK} \bullet \mathrm{CEN}$ included the development of an electrochemical sensor for the in situ measurement of the oxygen concentration in LBE during small scale evaporation experiments, a more detailed investigation of polonium evaporation from LBE as function of moisture content of the carrier gas, an attempt to couple transpiration experiments to a mass spectrometer to facilitate identification of the molecules evaporated from LBE, and the development of a thermodynamical model based on Gibbs Energy minimization (GEM) that allows an assessment of the complete chemical system of the LBE-cooled nuclear reactor including the coolant, the cover gas and all relevant impurities such as corrosion products of the structural material and radionuclides formed by activation. ${ }^{[41]}$ At University of Gent theoretical studies were performed to establish a method that allows to reliably predict the stability of polonium-containing molecules in the gas phase. The results from SEARCH indicated that while DFT proved to be adequate to describe the adsorption interaction of monoatomic polonium with noble metal surfaces, it is not suitable for a reliable calculation of thermodynamic properties of polonium-containing molecules. ${ }^{[42]}$ Therefore, a combination of more sophisticated methods had to be applied that properly account for electron correlation and the spin-orbit effects that are particularly important for heavy elements such as $\mathrm{Pb}, \mathrm{Bi}$ and Po. The new calculation routine developed within MYRTE was proven to reliably predict temperature dependent thermodynamic properties of diatomic polonium-containing molecules. ${ }^{[43]}$ Feeding these data into a GEM routine to evaluate the equilibrium gas phase composition over a polonium-containing LBE melt indicates that indeed, as postulated already from the data shown in Fig. 1, lead polonide, PbPo, is the dominating polonium-containing gas phase species. This result nicely shows how the methods developed and the experimental and theoretical results obtained in the collaboration of SCK $\bullet \mathrm{CEN}$, University of Gent and LRC converge.

The experimental studies performed at LRC within the MYRTE project aimed not only at the characterisation of the evaporation and deposition behaviour of polonium. The methods devised originally for the study of polonium were refined and adapted for similar investigations on the behaviour of the prominent volatile fission product elements iodine and caesium in LBE. The methodological improvements included handling of LBE samples and performing transpiration experiments in an inert gas glove box as well as reduction of LBE by contact with hot tantalum prior to the experiments. This is especially important for experiments with caesium and avoids the oxidation of the radiotracer as well as the formation of oxide layers on the surface of the samples, which may influence the evaporation process. Furthermore, the thermochromatography apparatus was upgraded by installing gas purification devices for the studies in dry carrier gases. More elaborate sample preparation and analysis methods were also developed to assure homogeneity of the samples and to speed up the evaluation of the results and increase their reliability. ${ }^{[44-51]}$

Thermochromatography experiments were performed not only on specimens containing the radionuclide to be studied in more or less pure form. Instead, also samples containing the nuclide dissolved in LBE were studied to clarify the influence of the liquid metal solvent on gas phase speciation and adsorption. Furthermore, the adsorption of the evaporated radionuclides on the steel used as main construction material of the MYRRHA reactor was investigated to provide the fundamental data needed to estimate the adhesion of released radioactive material on the reactor walls. Thermochromatography studies on iodine evaporated from LBE indicate that in helium and hydrogen gas bismuth monoiodide is formed and deposited at relatively low temperatures $\left(100-180{ }^{\circ} \mathrm{C}\right) .{ }^{[44,52]}$ In oxidising atmosphere, even more volatile species such as monatomic iodine and iodine oxides are formed. However, the adsorption of iodine evaporated from LBE 
on silver surfaces is much stronger, indicating that silver coated surfaces can be used to efficiently capture the iodine species evaporated from LBE. ${ }^{[4,53]}$ Experiments with caesium-doped LBE indicate that the caesium released from LBE is not adsorbed to steel and fused silica surfaces in thermochromatography experiments but rather reacts with these surfaces at temperatures between 400 and $700{ }^{\circ} \mathrm{C}$, leading to a fixation of the volatile species. ${ }^{[44,54]}$

Similar studies performed for polonium revealed that polonium, when it is evaporated in elemental form from samples that do not contain elements of the LBE matrix, adsorbs to steel slightly more strongly than to fused silica surfaces. More importantly, the formation of volatile species observed in similar experiments in fused silica columns with moist inert and reducing carrier gases was not observed in steel columns, indicating that the steel used as construction material for MYRRHA can suppress the formation of these species. ${ }^{[5]}$ However, when using LBE samples containing highly dilute polonium as sources in otherwise similar thermochromatography experiments, the tendency to form volatile polonium species was increased compared to the experiments with matrix-free polonium samples. ${ }^{[41,56]}$ This indicates that the formation of the volatile polonium species is an intricate process influenced by properties of the matrix, the adsorbing surface and the composition of the carrier gas.

Additional thermochromatography experiments were performed to investigate the transport and deposition of polonium in vacuum, with the goal to understand its behaviour in case of leaks enabling its migration into the proton beam guide of the MYRRHA accelerator. ${ }^{[44,57]}$ This study revealed that under vacuum conditions no particularly volatile polonium species form. The experimental data can be fully explained by Monte Carlo Simulations assuming $\mathrm{PbPo}$ as transported species with an adsorption enthalpy of about $-160 \mathrm{~kJ} / \mathrm{mol}$, similar to the value also obtained in gas thermochromatography. ${ }^{[56]}$

In parallel to the thermochromatography experiments, a large number of transpiration experiments were performed at LRC within MYRTE, with the aim of deriving thermodynamical data for the liquid gas equilibrium established over dilute solutions of iodine and caesium in LBE. For iodine, a vast number of experiments were performed under variation of parameters such as temperature, carrier gas composition and flow rate, LBE purity and oxygen content, and iodine concentration. The preliminary results show good consistency and no large influence of LBE purity, oxygen content and carrier gas composition. ${ }^{[41,58]}$ The Henry constants of iodine over dilute solution in LBE determined from the evaporation data are 7 to 8 orders lower than the equilibrium vapour pressure of pure iodine, indicating a strong retention of iodine in LBE. Comparing the Henry constants determined for iodine in LBE with vapour pressure data of pure lead and bismuth iodides indicates that the volatility of iodine dissolved in LBE is similar to that of the pure compounds $\mathrm{BiI}$ and $\mathrm{PbI}_{2} \cdot{ }^{[41,58]}$ This is consistent with the assumption that iodine dissolved in LBE is bound to the solvent atoms $\mathrm{Pb}$ and $\mathrm{Bi}$ with similar strength as in the pure lead and bismuth iodides. Similar but less detailed studies were also performed for caesium-containing LBE samples. The results indicate significant retention of caesium in LBE. ${ }^{441,47]}$

The results of iodine and caesium transpiration experiments are currently under final evaluation. They will be used to determine temperature-dependent Henry constant data for the iodine-LBE and caesium-LBE systems that will be integrated into the thermodynamic model of the MYRRHA reactor developed at $\mathrm{SCK} \cdot \mathrm{CEN}$. This thermodynamic model will be used extensively in the safety assessment of MYRRHA to predict which chemical phenomena such as evaporation of volatile molecular species or precipitation of insoluble phases are likely to occur in the reactor in normal operation and accident scenarios.

\section{Future Perspectives of Radionuclide Chemistry in Heavy Liquid Metals: H2020 Projects PATRICIA and PASCAL}

While some of the most urgent questions with respect to the chemical behaviour of radionuclides in lead and LBE have been answered in the last two decades, many phenomena still need to be understood in more detail, and a number of new questions were raised by results obtained within MYRTE and the preceding projects. This stimulated the two new EURATOM Horizon 2020 projects PATRICIA (Partitioning And Transmuter Research Initiative in a Collaborative Innovation Action) and PASCAL (Proof of Augmented Safety Conditions in Advanced Liquid-metal-cooled systems). The projects have been started while the current article was in revision/typesetting. These projects are aimed to answer remaining open questions resulting from previous research, but also to address problems that have never been tackled before. Both projects see an increased number of partners working on topics related to the coolant chemistry within the realm of heavy liquid metal reactors, reflecting an increased interest in the subject.

In the PATRICIA project, a new partner will join the established collaboration between $\mathrm{SCK} \cdot \mathrm{CEN}$, University of Gent and the LRC of PSI: The Joint Research Centre of the European Commission (JRC) will study the retention of tellurium, a major fission product and homologue of the hazardous polonium, in LBE using Knudsen Effusion Mass spectrometry (KEMS). Additionally, JRC will attempt to characterise tellurium hydroxides and oxy-hydroxides by matrix isolation combined with Raman and UV-Vis spectroscopy.

At LRC, polonium evaporation from LBE will be studied using LBE samples from the MEGAPIE experiment. These samples are unique in that they contain all the impurities that are generated or incorporated in the LBE by nuclear reactions and corrosion processes in a high power spallation target. Goal of this study is to find out whether the impurities generated during operation of the spallation target influence the evaporation behaviour of polonium. Furthermore, LRC will assess the evaporation of rhodium from LBE using radiotracers present in the LBE from MEGAPIE. Spectroscopic data obtained from transpiration experiments in the MYRTE project will be evaluated to extract data on thallium evaporation from LBE. Finally, LRC will attempt to synthesize LBE samples doped with the elements rhenium, rhodium and osmium, with the purpose of studying their evaporation from the liquid metal. Radionuclides of these elements are formed in non-negligible amounts in the MYRRHA reactor, and it is suspected that they could evaporate from the liquid metal in form of volatile oxides.

University of Gent will continue its research on quantum chemistry calculations to determine the stability of polonium containing molecules. Unfortunately, the approach successfully used to characterise diatomic polonium molecules in MYRTE is computationally too expensive to be used for calculations on the polonium hydroxides and oxy-hydroxides suspected to be causing the increased volatility of polonium in moist atmospheres. To overcome the computational limitations, the group at University of Gent proposes to use a machine learning algorithm trained to predict high quality thermodynamic data from computationally less expensive DFT calculations.

At $\mathrm{SCK} \cdot \mathrm{CEN}$, a coupled simulation platform will be developed, combining high-fidelity chemistry solver based on GEM and established CFD packages. This tool is intended to provide a quantitative understanding of the corrosion product behaviour in HLM cooled systems, from their corrosion source in the hottest regions in the reactor, via their transport and physicochemical interactions in the bulk of the coolant flow, to their sink. Such information is invaluable for the safe operation of MYRRHA. Furthermore, $\mathrm{SCK} \cdot \mathrm{CEN}$ will continue to investigate the release kinetics of polonium from LBE in the presence of water vapour using transpiration type evaporation experiments. 
In the PASCAL project, evaporation experiments will be performed on more complex systems containing two different radionuclides dissolved in LBE. In particular, LRC will study the influence of the interaction of caesium and iodine dissolved in LBE on their evaporation. This study was triggered by results of thermodynamic assessments indicating that evaporation of these two fission products could be enhanced by the formation of a caesium iodide phase that separates from the liquid metal. LRC will also study the evaporation and deposition of the important fission product and polonium homologue tellurium from LBE using the transpiration method and thermochromatography. This study is complementary to the KEMS studies performed at JRC in the PATRICIA project and aims at the characterisation of particularly volatile species that might form in moist atmospheres in analogy to the behaviour of polonium. In parallel, $\mathrm{SCK} \cdot \mathrm{CEN}$ intends to characterise the fission product molecules evaporated from the LBE using molecular beam mass spectrometry. Within PASCAL, it is planned to investigate iodine, tellurium and caesium gas molecules released from the heavy liquid metals lead and LBE, with the aim to identify the different molecules forming under variation of the gas phase composition.

Other subtasks of PATRICIA and PASCAL will extend the scope of the chemical studies related to the behaviour of lead and LBE and the impurities contained therein. One prominent topic, which is going to be investigated in a collaboration of TU Delft, Chalmers University in Gothenburg and JRC in Karlsruhe, is studying the interaction of nuclear fuel with the liquid metal in order to understand to what extent and by which mechanisms radioactive material can be transferred from the fuel to the coolant. Furthermore, the first systematic study on the formation of lead and LBE aerosols and their transport in a gas stream will be performed in a collaboration of groups at $\mathrm{SCK} \cdot \mathrm{CEN}$ and KTH Stockholm.

\section{Summary and Conclusion}

Within the last two decades, the chemistry of radionuclides in heavy liquid metals used in nuclear systems evolved from simple studies, answering the most urgent questions raised in the licensing procedure of the MEGAPIE experiment, to more detailed, precise and complex investigations necessary for the safety analysis of larger facilities such as the MYRRHA reactor. Understanding the chemical processes occurring in these heavy liquid metals remains a challenging subject at the borderline of physical and inorganic chemistry, radiochemistry, materials science and metallurgy that will be of crucial importance for the safe and reliable operation of all nuclear systems utilizing lead or LBE as coolant and/ or spallation target material. The Laboratory of Radiochemistry at Paul Scherrer Institut is particularly well suited to contribute to this subject because of its vast experience in liquid metal and gas phase chemistry methods, combined with unique facilities for the production and handling of samples containing the radionuclides of interest as well as the radioanalytical methods needed for their study. Therefore, LRC will strive to continue its efforts in this field, in order to monitor and support the development of novel nuclear technologies that may help to successfully manage a safe and sustainable energy production. Another important aspect is providing opportunities for next generation scientists to acquire a radiochemical education that is at the forefront of novel reactor technology. This is particularly important for the preservation of nuclear competence in Switzerland.

\section{Acknowledgements}

The research summarized in the present article has been funded by the European Commission within the projects MEGAPIETEST ( $5^{\text {th }}$ EURATOM Framework Programme, Contract No. FIKWCT-2001-00159), SEARCH (7 ${ }^{\text {th }}$ EURATOM Framework Programme, Contract No. 295736) and MYRTE (EURATOM Horizon 2020 Framework Programme, Grant Agreement No. 662186)
[1] a) U.S. DOE Nuclear Energy Research Advisory Committee, Generation IV International Forum. A technology roadmap for Generation IV nuclear energy systems. USA: U.S. DOE Nuclear Energy Research Advisory Committee, Generation IV International Forum; Report No.: GIF-00200, 2002; b) EURATOM, Contribution to the Generation IV International Forum Systems in the period 2005-2014 and future outlook, EUR 28391 EN, Publications Office of the European Union, Luxembourg, 2017. c) GIF forum. Available at: https://www.gen-4.org/gif/jcms/c_9261/home (accessed July 17, 2020)

[2] J. R. Weeks, Nucl. Eng. Des. 1971, 15, 363 , https://doi.org/10.1016/0029-5493(71)90075-6.

[3] A. Alemberti, M. Frignani, G. Villabruna, P. Agostini, G. Grasso, M. Tarantino, I. Turcu, M. Constantin, D. Diaconu, F. Di Gabriele, N. Witzanyova, M. Krykova, 'ALFRED and the Lead Technology Research Infrastructure', European research reactor Conference, RRFM2015, Conference Proceedings, Bucharest, April 19-23, 2015

[4] Status of Accelerator Driven Systems Research and Technology Development, IAEA-TECDOC-1766, International Atomic Energy Agency, Vienna, 2015.

[5] 'Handbook on Lead-bismuth Eutectic Alloy and Lead Properties, Materials Compatibility, Thermal-hydraulics and Technologies', Ed. C. Fazio, Nuclear Energy Agency No. 7268, Organisation for Economic Co-operation And Development: Paris, 2015

[6] A. Aerts, B. Gonzalez Prieto, J. Neuhausen, 'Behaviour of Spallation, Activation and Fission Products in LBE', Reference Module in Materials Science and Materials Engineering, Elsevier, 2019, https://doi.org/10.1016/B978-0-12-803581-8.11612-1.

[7] G. S. Bauer, Nucl. Instr. Meth. Phys. Res. B 1998, 139, 65, https://doi.org/10.1016/S0168-583X(97)00956-7.

[8] G. S. Bauer, M. Salvatores, G. Heusener, J. Nucl. Mater. 2001, 296, 17, https://doi.org/10.1016/S0022-3115(01)00561-X.

[9] B. Eichler, 'Die Flüchtigkeitseigenschaften des Poloniums', PSI-Report No. 02-12, Paul Scherrer Institut, Villigen, Switzerland, 2002.

[10] L. S. Brooks, J. Am. Chem. Soc. 1955, 77, 3211, https://doi.org/10.1021/ja01617a014.

[11] A. S. Abakumov, Z. V. Ershova, Radiokhimiya 1974, 16, 397; Soviet Radiochemistry, 1974, 16, 396.

[12] B. Eichler, J. Neuhausen, 'Verflüchtigungspfade des Poloniums aus einem $\mathrm{Pb}-\mathrm{Bi}$-Spallationstarget (Thermochemische Kalkulation)', PSI-Report Nr. 04-06, Paul Scherrer Institut, Villigen, Switzerland, 2004

[13] F. R. de Boer, R. Boom, W. C. M. Mattens, A. R. Miedema, A. K. Niessen, 'Cohesion in Metals, Transition Metal Alloys', North-Holland, Amsterdam, 1988.

[14] J. Neuhausen, B. Eichler, 'Extension of Miedema's Macroscopic Atom Model to the Elements of Group 16 (O, S, Se, Te, Po)', PSI Report 03-13, Paul Scherrer Institut, Villigen, Switzerland, 2003.

[15] a) C. B. Alcock, G. W. Hooper, 'Physical Chemistry of Process Metallurgy', Interscience, New York, 1961, p. 325; b) O. Kubaschewski, E. L. Evans, 'Metallurgical Thermochemistry', Pergamon Press, London, New York, Paris, Los Angeles, 1958; c) J. L. Margrave, 'Physicochemical Measurements at High Temperatures', Butterworths, London, 1959, pp. 225-246; d) U. Merten, J. Phys. Chem. 1959, 63, 443, https://doi.org/10.1021/j150573a028.

[16] J. Neuhausen, U. Köster, B. Eichler, Radiochim. Acta 2004, 92, 917, https://doi.org/10.1524/ract.92.12.917.55105.

[17] a) J. Neuhausen, B. Eichler, Radiochim. Acta 2005, 93, 155, https://doi.org/10.1524/ract.93.3.155.61609; b) J. Neuhausen, Nucl. Instrum. Methods Phys. Res., Sect. A 2006, 562, 702, https://doi.org/10.1016/j.nima.2006.02.025; c) J. Neuhausen, B. Eichler, Radiochim. Acta 2006, 94, 239, https://doi.org/10.1524/ract.2006.94.5.239.

[18] a) J. Neuhausen, 'Gas Phase Concentrations of Volatile Nuclear Reaction Products in the MEGAPIE Expansion Tank', PSI Report TM-18-0502, Paul Scherrer Institut, Villigen, Switzerland, 2005; b) J. Neuhausen, 'Reassessment of the Rate of Evaporation of Polonium from Liquid Eutectic Lead Bismuth Alloy', PSI Report TM-18-05-01, Paul Scherrer Institut, Villigen, Switzerland, 2005.

[19] F. Groeschel, J. Neuhausen, A. Fuchs, A. Janett, 'Intermediate Safety Report, Treatment of the Reference Accident Case', Deliverable D14 of WP1 of the MEGAPIE-TEST programme, 5th EURATOM Framework Programme, Paul Scherrer Institut, Villigen, Switzerland, 2006.

[20] W. Wagner, F. Groeschel, K. Thomsen, H. Heyck, J. Nucl. Mater. 2008, 377 , 12, https://doi.org/10.1016/j.jnucmat.2008.02.057.

[21] C. Fazio, F. Gröschel, W. Wagner, K. Thomsen, B. L. Smith, R. Stieglitz, L. Zanini, A. Guertin, A. Cadiou, J. Henry, P. Agostini, Y. Dai, H. Heyck, S. Dementjev, S. Panebianco, A. Almazouzi, J. Eikenberg, A. Letourneau, J. C. Toussaint, A. Janett, Ch. Perret, S. Joray, J. Patorski, W. Leung, P. Meloni, P. Turroni, A. Zucchini, G. Benamati, J. Konys, T. Auger, A. Gessi, D. Gorse, I. Serre, A. Terlain, J.-B. Vogt, A. Batta, A. Class, X. Cheng, F. Fellmoser, M. Daubner, S. Gnieser, G. Grötzbach, R. Milenkovic, C. Latgé, J. U. Knebel, Nucl. Eng. Design 2008, 238, 1471, https://doi.org/10.1016/j.nucengdes.2007.11.006

[22] a) M. Wohlmuther, W. Wagner, J. Nucl. Mater. 2012, 431, 10 https://doi.org/10.1016/j.jnucmat.2011.11.024. b) Y. Dai, M. Wohlmuther, V. 
Boutellier, S. Hahl, A. Lagotzki, H. Leu, H. P. Linder, R. Schwarz, A. Spahr, L. Zanini, D. Kuster, D. Gavillet, W. Wagner, J. Nucl. Mater. 2016, 468, 221, https://doi.org/10.1016/j.jnucmat.2015.08.026.

[23] B. Hammer-Rotzler, 'Analysis of the nuclide Inventory in MEGAPIE, a proton irradiated lead-bismuth eutectic spallation target, $\mathrm{PhD}$-Thesis, University of Bern, 2015.

[24] D. Schumann, E. A. Maugeri, R. Dressler, Chimia 2020, 74, 932.

[25] B. Hammer, J. Neuhausen, V. Boutellier, H. P. Linder, N. Shcherbina, M. Wohlmuther, A. Türler, D. Schumann, J. Nucl. Mater. 2014, 450, 278, https://doi.org/10.1016/j.jnucmat.2013.09.016.

[26] B. Hammer, D. Schumann, J. Neuhausen, M. Wohlmuther, A. Türler, Nucl. Data Sheets 2014, 119, 280, https://doi.org/10.1016/j.nds.2014.08.077.

[27] B. Hammer-Rotzler, J. Neuhausen, V. Boutellier, M. Wohlmuther, L. Zanini, J.-C. David, A. Türler, D. Schumann, Eur. Phys. J. Plus 2016, 131(7), 233, https://doi.org/10.1140/epjp/i2016-16233-1.

[28] B. Hammer, J. Neuhausen, V. Boutellier, M. Wohlmuther, A. Türler, D. Schumann, Anal. Chem. 2015, 87, 5656, https://doi.org/10.1021/acs.analchem.5b00955.

[29] B. Hammer-Rotzler, J. Neuhausen, C. Vockenhuber, V. Boutellier, M. Wohlmuther, A. Türler, D. Schumann, Radiochim. Acta 2015, 103(11), 745, https://doi.org/10.1515/ract-2015-2420.

[30] a) H. Aït Abderrahim, P. Baeten, D. De Bruyn, R. Fernandez, Energy Conv. Manag. 2012, 63, 4, https://doi.org/10.1016/j.enconman.2012.02.025; b) MYRRHA website. Available at: https://myrrha.be/ (accessed July 17, 2020)

[31] Organisation for economic co-operation and development, 'Handbook on Lead-bismuth Eutectic Alloy and Lead Properties, Materials Compatibility, Thermal-hydraulics and Technologies' Nuclear Energy Agency No. 7268, Organisation For Economic Co-operation And Development. Paris, 2015.

[32] SEARCH website, Available at: https://search.sckcen.be/ (accessed July 17, 2020)

[33] I. Zvara, 'The Inorganic Radiochemistry of Heavy Elements: Methods for Studying Gaseous Compounds' Springer Netherlands, 2008

[34] M. Rizzi, J. Neuhausen, R. Eichler, A. Türler, T. Melo Mendonça, T. Stora, B. Gonzalez Prieto, A. Aerts, D. Schumann, J. Nucl. Mater. 2014, 450, 304, https://doi.org/10.1016/j.jnucmat.2014.01.047.

[35] B. Gonzalez Prieto, PhD Thesis. KU Leuven, 2015.

[36] a) B. Gonzalez Prieto, J. Lim, A. Mariën, K. Rosseel, J. A. Martens, J. Van den Bosch, J. Neuhausen, A. Aerts, J. Radioanal. Nucl. Chem. 2014, 302, 195, https://doi.org/10.1007/s10967-014-3264-1; b) B. Gonzalez Prieto, J. Lim, K. Rosseel, J. A. Martens, A. Aerts, J. Radioanal. Nucl. Chem. 2016, 309, 597, https://doi.org/10.1007/s10967-015-4670-8.

[37] E. A. Maugeri, J. Neuhausen, R. Eichler, D. Piguet, T. Melo Mendonça, Th. Stora, D. Schumann, J. Nucl. Mater. 2014, 450, 292 https://doi.org/10.1016/j.jnucmat.2013.11.024.

[38] a) E. A. Maugeri, J. Neuhausen, R. Eichler, R. Dressler, K. Rijpstra, S. Cottenier, D. Piguet, A. Vögele, D. Schumann, Radiochim. Acta 2016, 104, 757, https://doi.org/10.1515/ract-2016-2573; b) E. A. Maugeri, J. Neuhausen, R. Misiak, R. Eichler, R. Dressler, D. Piguet, A. Vögele, D. Schumann, Radiochim. Acta 2016, 104, 769, https://doi.org/10.1515/ract-2016-2575.

[39] K. Rijpstra, PhD Thesis, Gent University, 2014.

[40] MYRTE website, available at: https://myrte.sckcen.be/ (accessed July 21 2020)

[41] P. Planquart, Proceedings of International Workshop, available at https:// myrte.sckcen.belen/Deliverables, (accessed July 19, 2020).

[42] A. Van Yperen-De Deyne, K. Rijpstra, M. Waroquier, V. Van Speybroeck, S. Cottenier, J.Nucl. Mater. 2015, 458, 288, https://doi.org//10.1016/j.jnucmat.2014.11.064.

[43] M. A. J. Mertens, A. Aerts, I. Infante, J. Neuhausen, S. Cottenier, J. Phys. Chem. Letters 2019, 10, 2879, https://doi.org/10.1021/acs.jpclett.9b00824.

[44] E. Karlsson, PhD Thesis, University of Bern, 2020.

[45] I. I. Danilov, J. Neuhausen, A. Vögele, E. Müller, Annual Report LRC, Eds. A. Türler, R. Eichler, A. Blattmann, Paul Scherrer Institut, Villigen Switzerland, 2016, p. 15, available at https://www.psi.ch/en/lrc/annual-reports, (accessed July 21, 2020).

[46] R. Dressler, J. Neuhausen, I. I. Danilov, A. Türler, Annual Report LRC, Eds R. Eichler, A. Blattmann, Paul Scherrer Institut, Villigen Switzerland, 2017, p. 16, available at https://www.psi.ch/en/lrc/annual-reports, (accessed July $21,2020)$.
[47] I. I. Danilov, J. Neuhausen, A. Vögele, R. Eichler, A. Türler, Annual Report LRC, Eds. R. Eichler, A. Blattmann, Paul Scherrer Institut, Villigen Switzerland, 2017, p. 18, available at https://www.psi.ch/en/lrc/annual-reports, (accessed July 21, 2020).

[48] I. I. Danilov, J. Neuhausen, A. Vögele, R. Eichler, E. Müller, A. Türler, Annual Report LRC, Eds. R. Eichler, A. Blattmann, Paul Scherrer Institut, Villigen Switzerland, 2017, p. 20, available at https://www.psi.ch/en/lrc/annual-reports, (accessed July 21, 2020).

[49] I. I. Danilov, A. Vögele, D. Hermann, R. Dressler, R. Eichler, A. Türler, J. Neuhausen, Annual Report LRC, Eds. R. Eichler, A. Blattmann, Paul Scherrer Institut, Villigen Switzerland, 2018, p. 44, available at https://www.psi.ch/en/lrc/annual-reports, (accessed July 21, 2020).

[50] J. Neuhausen, I. I. Danilov, A. Vögele, Annual Report LRC, Paul Scherrer Institut, Villigen Switzerland, 2019, p. 52, available at https://www.psi.ch/en/lrc/annual-reports, (accessed July 21, 2020).

[51] a) E. Karlsson, J. Neuhausen, R. Eichler, A. Vögele, A. Türler, J. Radioanal. Nucl. Chem. 2020, 326, 711, https://doi.org/10.1007/s10967020-07326-y; b) E. Karlsson, J. Neuhausen, I. I. Danilov, A. Vögele, R. Eichler, A. Türler, Annual Report LRC, Eds. R. Eichler, A. Blattmann, Paul Scherrer Institut, Villigen Switzerland, 2019, p. 48, available at https://www.psi.ch/en/lrc/annual-reports, (accessed July 21, 2020).

[52] a) E. Karlsson, J. Neuhausen, A. Vögele, R. Eichler, A. Türler, Annual Report LRC, Eds. A. Türler, R. Eichler, A. Blattmann, Paul Scherrer Institut, Villigen Switzerland, 2016, p. 11, available at https://www.psi.ch/en/lrc/annual-reports, (accessed July 21, 2020); b) E. Karlsson, J. Neuhausen, R. Eichler, A. Aerts, I. I. Danilov, A. Vögele, A. Türler, J. Radioanal. Nucl. Chem. 2020, https://doi.org/10.1007/s10967-020-07420-1

[53] E. Karlsson, J. Neuhausen, I. I. Danilov, A. Vögele, R. Eichler, A Türler, Annual Report LRC, Eds. R. Eichler, A. Blattmann, Paul Scherrer Institut, Villigen Switzerland, 2019, p. 50, available at https://www.psi.ch/en/lrc/annual-reports, (accessed July 21, 2020).

[54] E. Karlsson, A. Colldeweih, J. Neuhausen, R. Eichler, A. Türler, Annual Report LRC, Eds. A. Türler, R. Eichler, A. Blattmann, Paul Scherrer Institut, Villigen Switzerland, 2016, p. 13, available at https://www.psi.ch/en/lrc/annual-reports, (accessed July 21, 2020).

[55] E. A. Maugeri, J. Neuhausen, B. Gonzalez Prieto, A. Aerts, T. Melo Mendonça, Th. Stora, R. Eichler, Radiochim. Acta 2018, 106(2), 125, https://doi.org/10.1515/ract-2017-2807.

[56] a) B. Gonzalez Prieto, J. Neuhausen, R. Eichler, A. Vögele, D. Piguet, D. Schumann, Annual Report LRC, Eds. A. Türler, M. Schwikowski, A Blattmann, Paul Scherrer Institut, Villigen Switzerland, 2015, p. 51, available at https://www.psi.ch/en/lrc/annual-reports, (accessed July 21, 2020); b) B. Gonzalez Prieto, J. Neuhausen, R. Eichler, A. Vögele, D. Piguet, D. Schumann, Annual Report LRC, Eds. A. Türler, M. Schwikowski, A. Blattmann, Paul Scherrer Institut, Villigen Switzerland, 2015, p. 52, available at https://www.psi.ch/en/lrc/annual-reports, (accessed July 21, 2020); c) B. Gonzalez Prieto, J. Neuhausen, R. Eichler, A. Vögele, D. Piguet, D. Schumann, Annual Report LRC, Eds. A. Türler, M. Schwikowski, A Blattmann, Paul Scherrer Institut, Villigen Switzerland, 2015, p. 53, available at https://www.psi.ch/en/lrc/annual-reports, (accessed July 21, 2020).

[57] a) E. Karlsson, J. Neuhausen, A. Aerts, I. I. Danilov, R. Eichler, A Türler, A. Vögele, Appl. Radiat. Isot., accepted for publication; b) E. Karlsson, A. Vögele, R. Eichler, A. Aerts, D. Hermann, A. Türler, J. Neuhausen, Annual Report LRC, Eds. R. Eichler, A. Blattmann, Paul Scherrer Institut, Villigen Switzerland, 2018, p. 48, available at https://www.psi.ch/en/lrc/annual-reports, (accessed July 21, 2020).

[58] I. I. Danilov, A. Vögele, D. Hermann, R. Eichler, A. Türler, J. Neuhausen, Annual Report LRC, Eds. R. Eichler, A. Blattmann, Paul Scherrer Institut, Villigen Switzerland, 2018, p. 46, available at https://www.psi.ch/en/lrc/annual-reports, (accessed July 21, 2020).

\section{License and Terms}

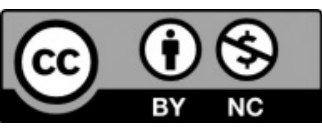

This is an Open Access article under the terms of the Creative Commons Attribution License CC BY NC 4.0. The material may not be used for commercial purposes.

The license is subject to the CHIMIA terms and conditions: (http:// chimia.ch/component/sppagebuilder/?view = page\&id=12).

The definitive version of this article is the electronic one that can be found at https://doi.org/10.2533/chimia.2020.976 